\title{
Supplementary Information: Land Surface Model influence on the simulated climatologies of temperature and precipitation extremes in the WRF v.3.9 model over North America
}

Almudena García-García ${ }^{1,2}$, Francisco José Cuesta-Valero ${ }^{1,2}$, Hugo Beltrami ${ }^{1}$, Fidel González-Rouco ${ }^{3}$, Elena García-Bustamante ${ }^{4}$, and Joel Finnis ${ }^{5}$

${ }^{1}$ Climate \& Atmospheric Sciences Institute, St. Francis Xavier University, Antigonish, Nova Scotia, Canada

${ }^{2}$ Environmental Sciences Program, Memorial University of Newfoundland, St. John's, Newfoundland, Canada

${ }^{3}$ Physics of the Earth and Astrophysics Department, IGEO (UCM-CSIC), Universidad Complutense de Madrid, Spain.

${ }^{4}$ Research Center for Energy, Environment and Technology (CIEMAT), Madrid, Spain.

${ }^{5}$ Department of Geography, Memorial University of Newfoundland, St. John's, Newfoundland, Canada

Correspondence: Hugo Beltrami (hugo@stfx.ca)

Table S1. Characteristics of the evaluation simulations employed in this analysis from three RCMs participating in the CORDEX project. The boundary conditions for these three simulations are from the ERA-Interim reanalysis.

\begin{tabular}{cccccc}
\hline CORDEX RCM & LSM & Vegetation Types & Spectral Nudging & Institution & Reference \\
\hline WRF & NOAH & 24 & Yes & NCAR & Skamarock et al. (2008) \\
RCA4 & RCA LSS & 12 & No & SMHI & Samuelsson et al. (2011) \\
CRCM-UQAM & CLASS3.5+ & 4 & No & UQAM & Martynov et al. (2013) \\
\hline
\end{tabular}

Table S2. Information on the visited websites for retrieving data or detailed information.

\begin{tabular}{ccc}
\hline Product & Website & Date of access \\
\hline ETCCDI & https://www.climdex.org/learn/indices/ & December, 2018 \\
NA-CORDEX & https://www.earthsystemgrid.org/search/cordexsearch.html & December, 2018 \\
NARR & https://nomads.ncdc.noaa.gov/data/narr/ & August, 2017 \\
ARW-WRF Version 3.9 & http://www2.mmm.ucar.edu/wrf/users/download/get_source.html & August, 2017 \\
\hline
\end{tabular}



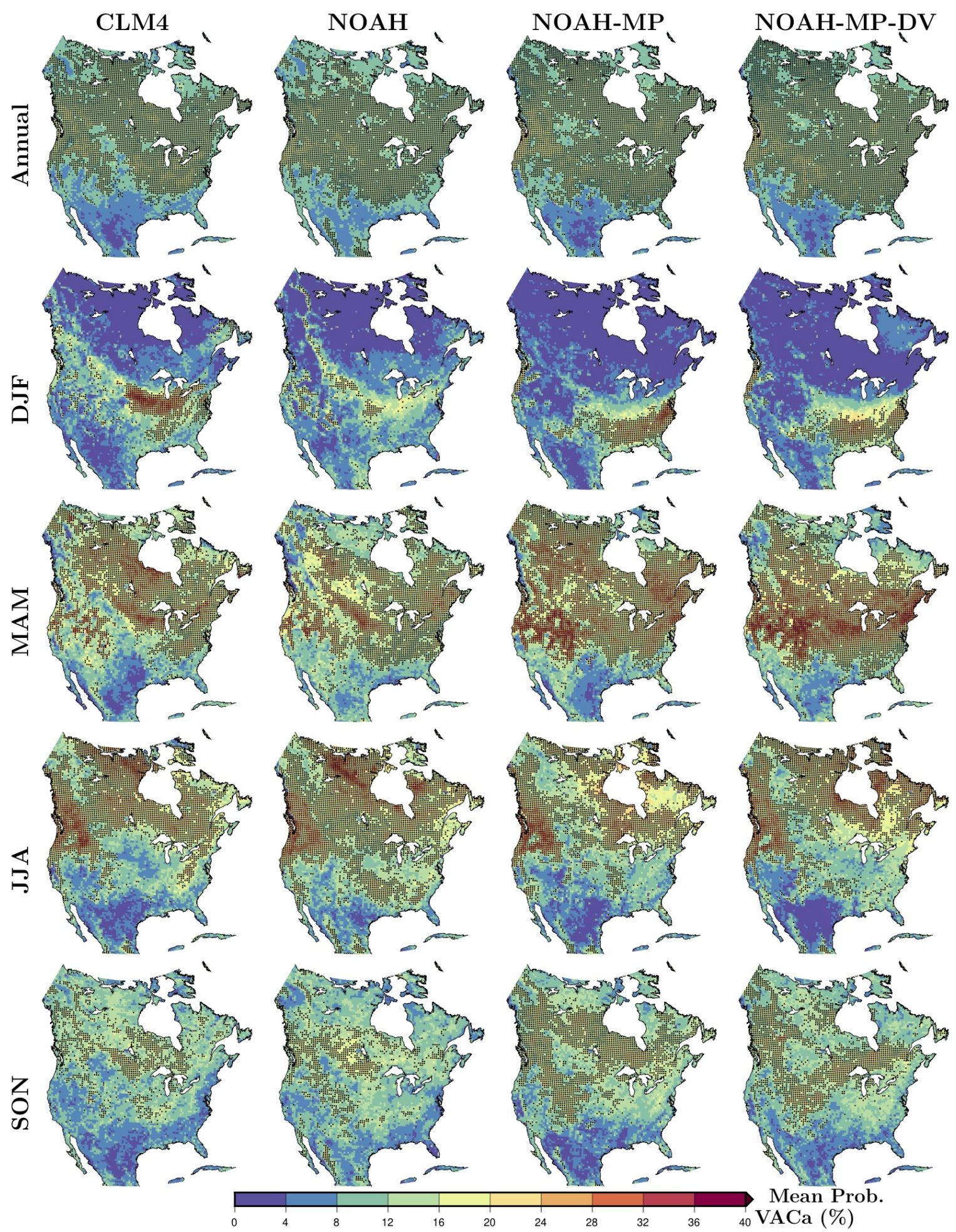

Figure S1. Mean frequency of occurrence for the $\mathrm{VAC}_{a}$ category associated with atmospheric control events for each simulation annually and seasonally; DJF, MAM, JJA and SON. Black dots in the maps indicate VAC values larger than the 95th percentile of the randomly generated series. 

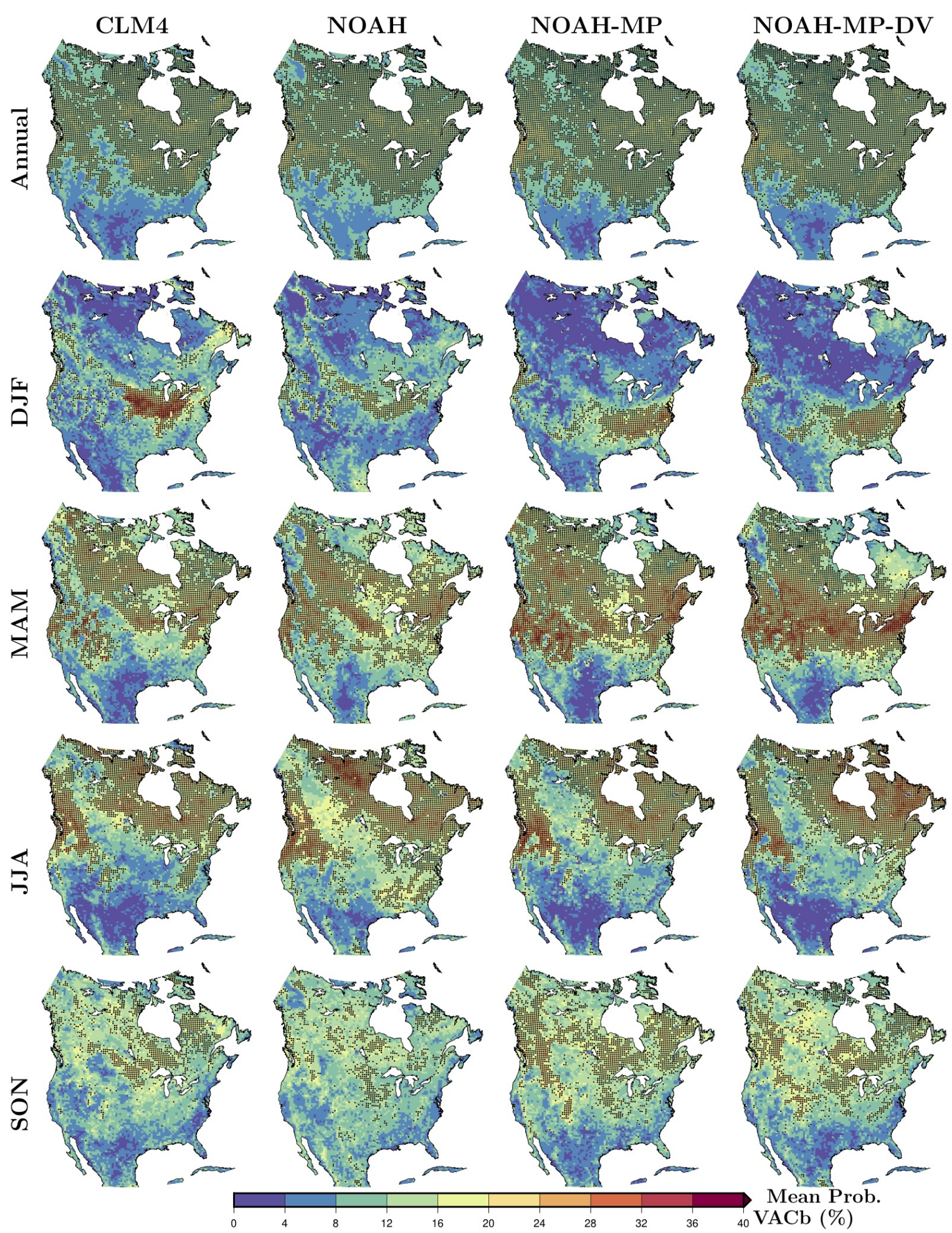

Figure S2. As in Figure S1 but for the $\mathrm{VAC}_{b}$ category. 

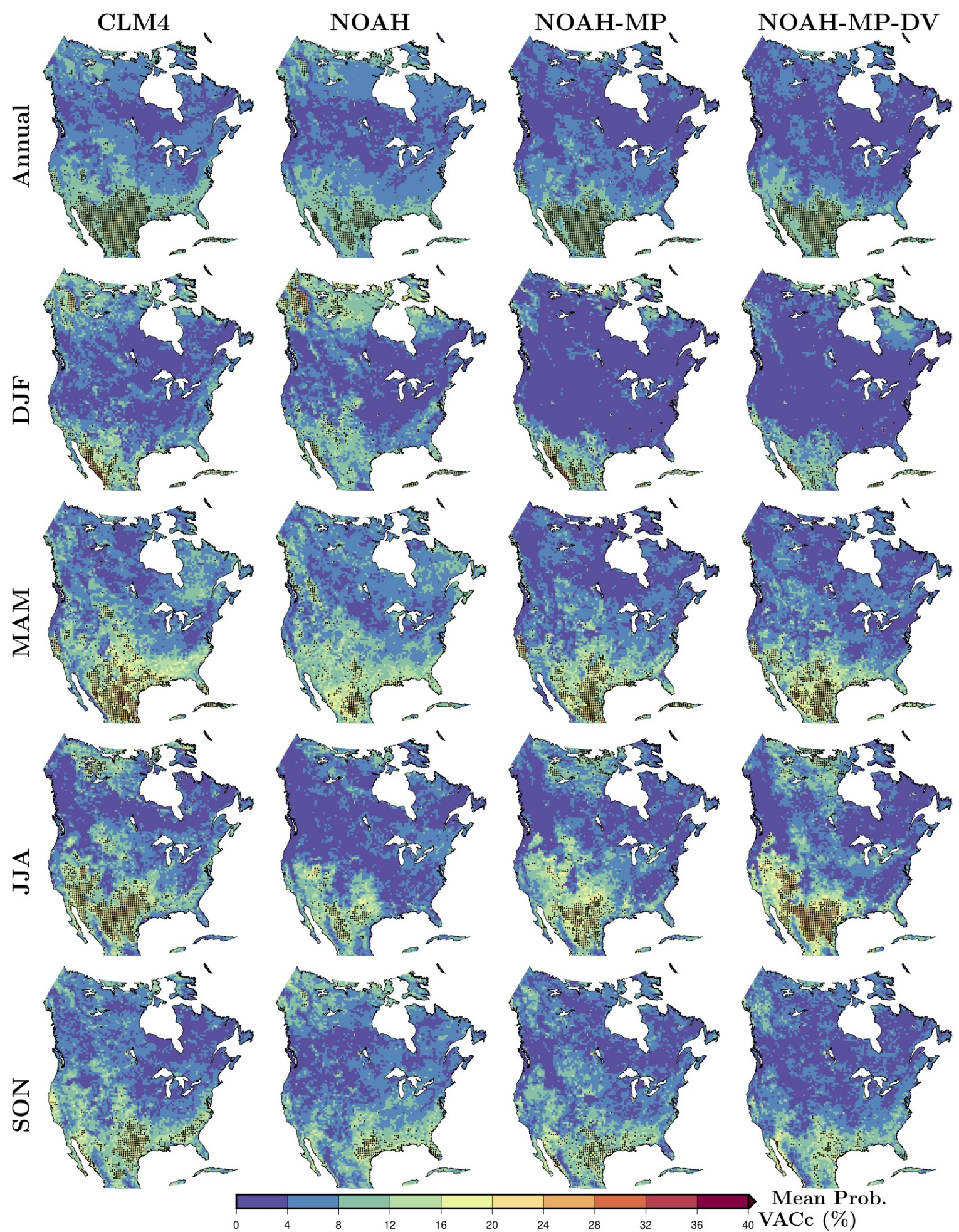

Figure S3. As in Figure $\mathrm{S} 1$ but for the $\mathrm{VAC}_{c}$ category. 

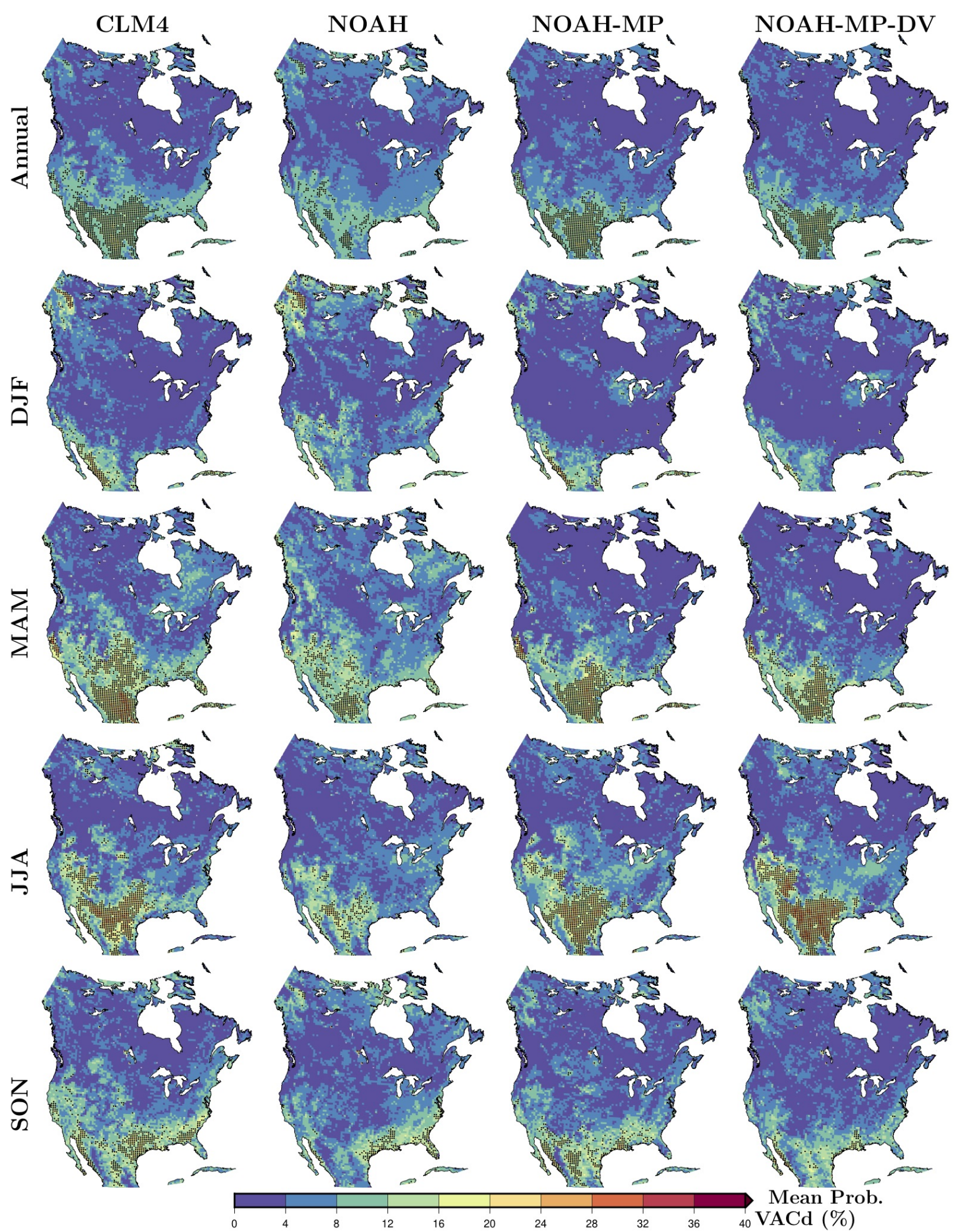

Figure S4. As in Figure S1 but for the $\mathrm{VAC}_{d}$ category. 

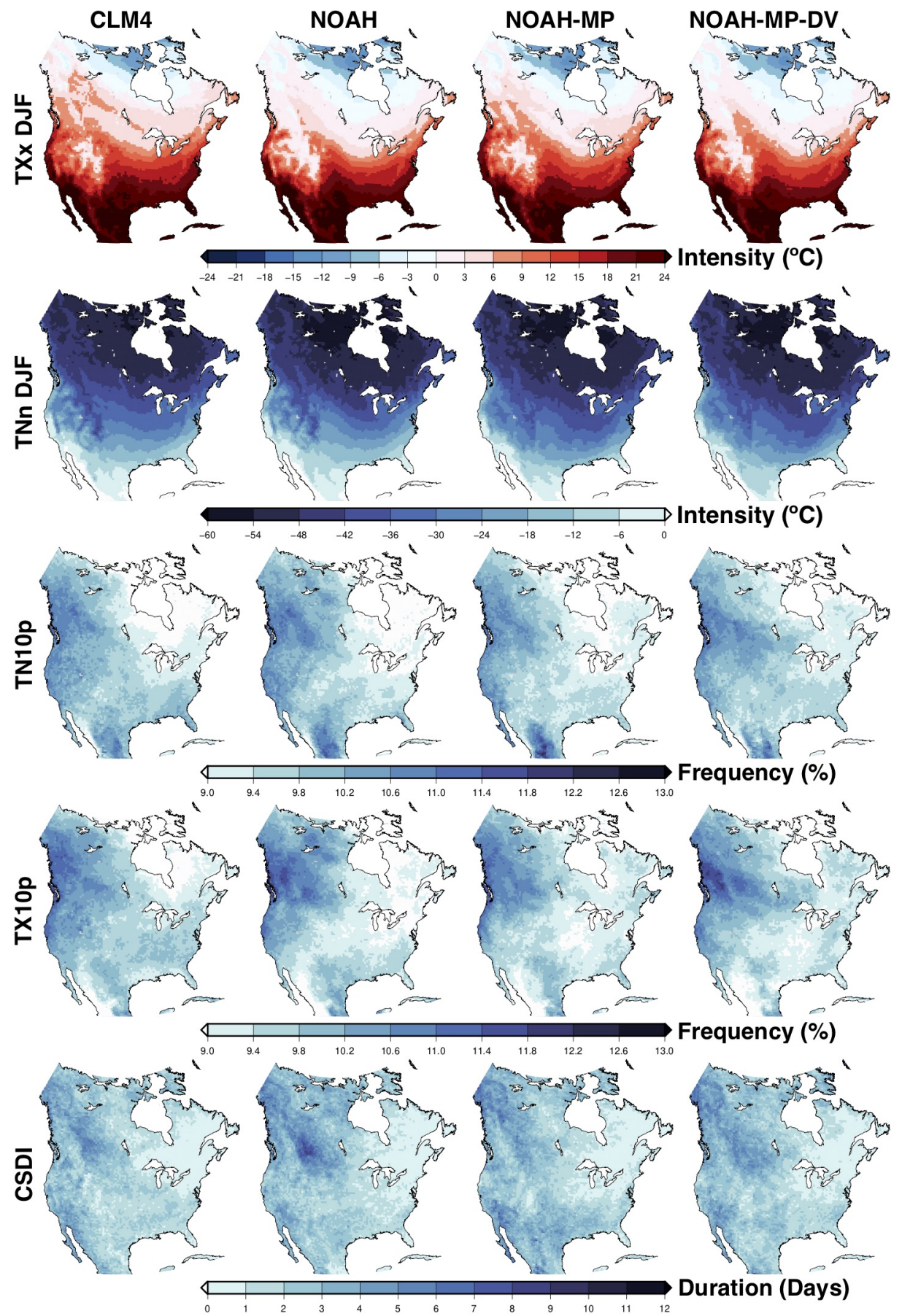

Figure S5. Climatologies of extreme indices associated with intensity, frequency, and duration of cold extreme temperature events for each simulation separately (Table 2). The indices are computed using the mean of each index from 1980 to 2012 for each simulation. 

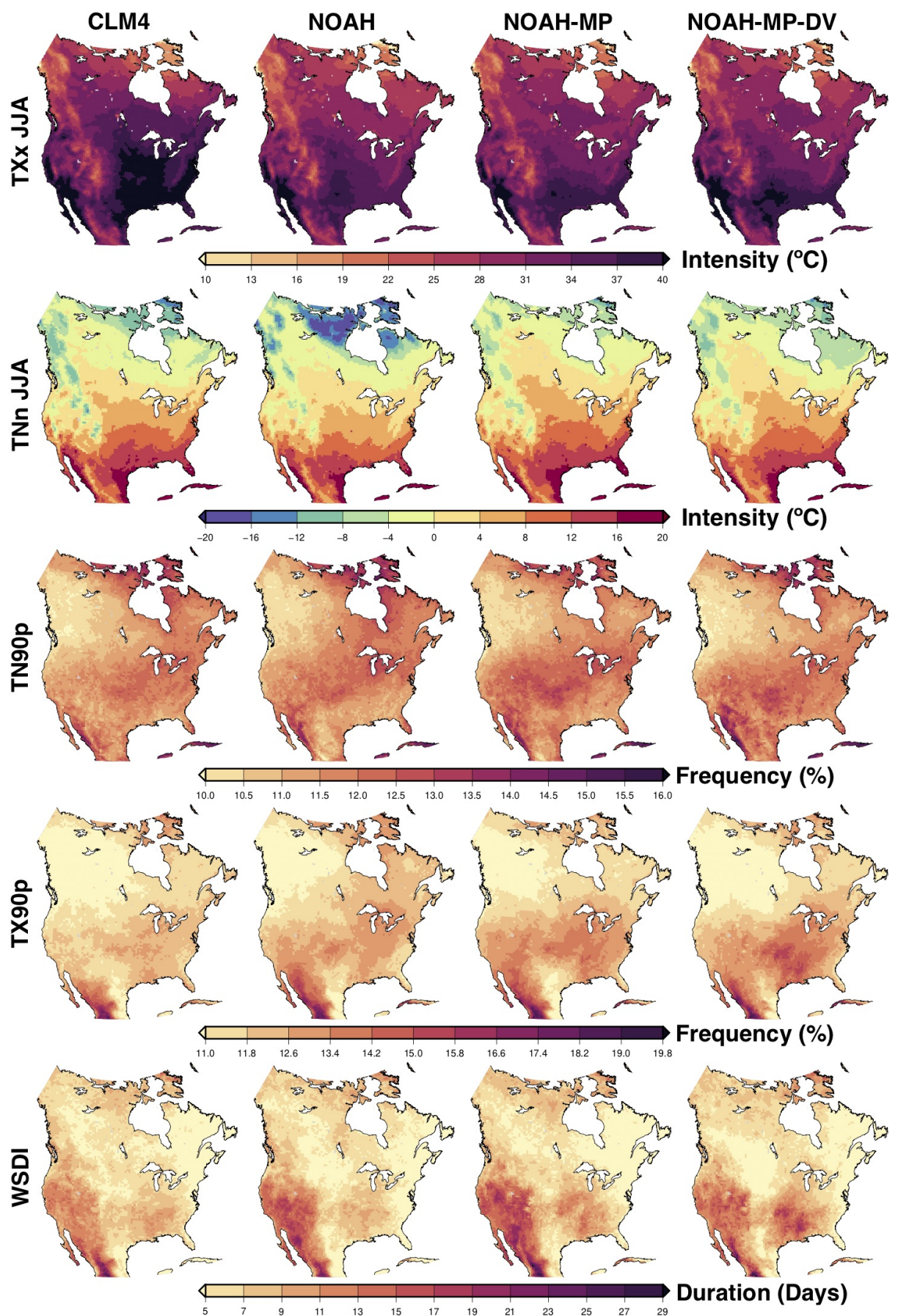

Figure S6. As in Figure S5 but for warm extreme temperature events. 

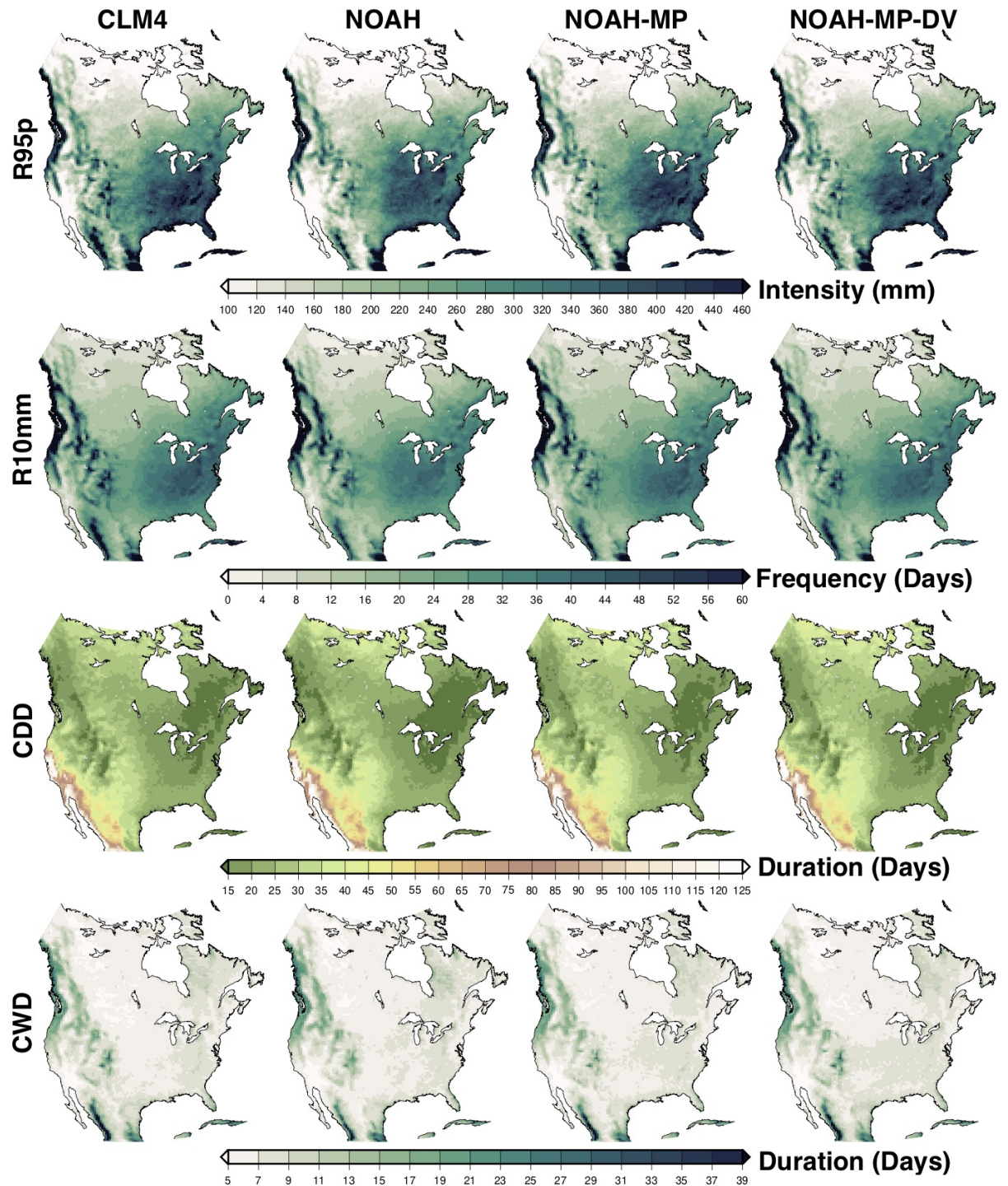

Figure S7. As in Figure S5 but for extreme precipitation events. 


\section{COLD EXTREME INDICES}
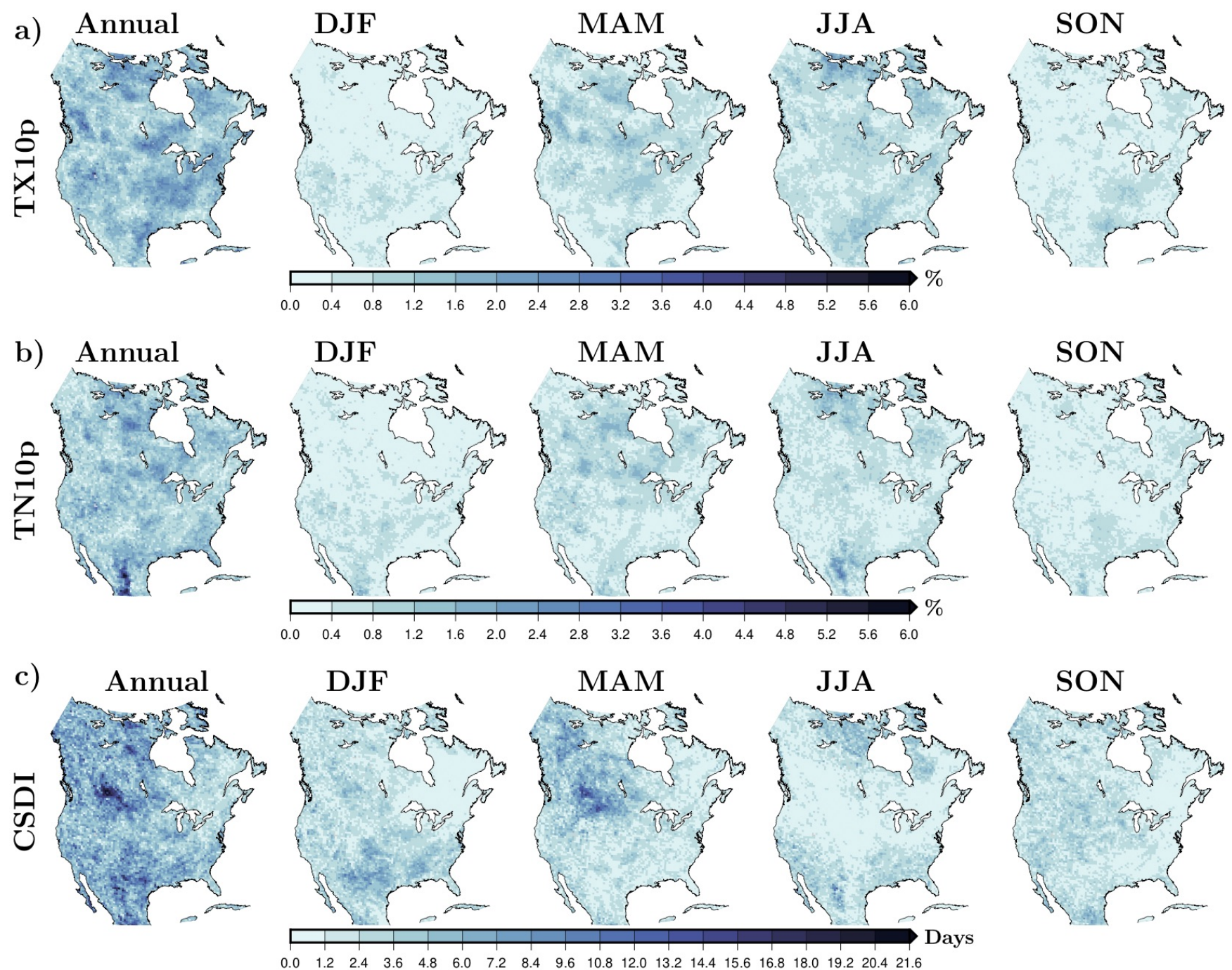

Figure S8. Seasonal component of the multi-model ranges across the WRF simulations (i.e., difference between the highest value and the lowest value of the simulation ensemble at each grid cell) for extreme indices associated with frequency (TX10p, panel a; TN10p, panel b), and duration (CSDI, panel c) of cold temperature extremes (Table 2). The range among simulations is computed using the mean of each index from 1980 to 2012 for each simulation. 


\section{WARM EXTREME INDICES}
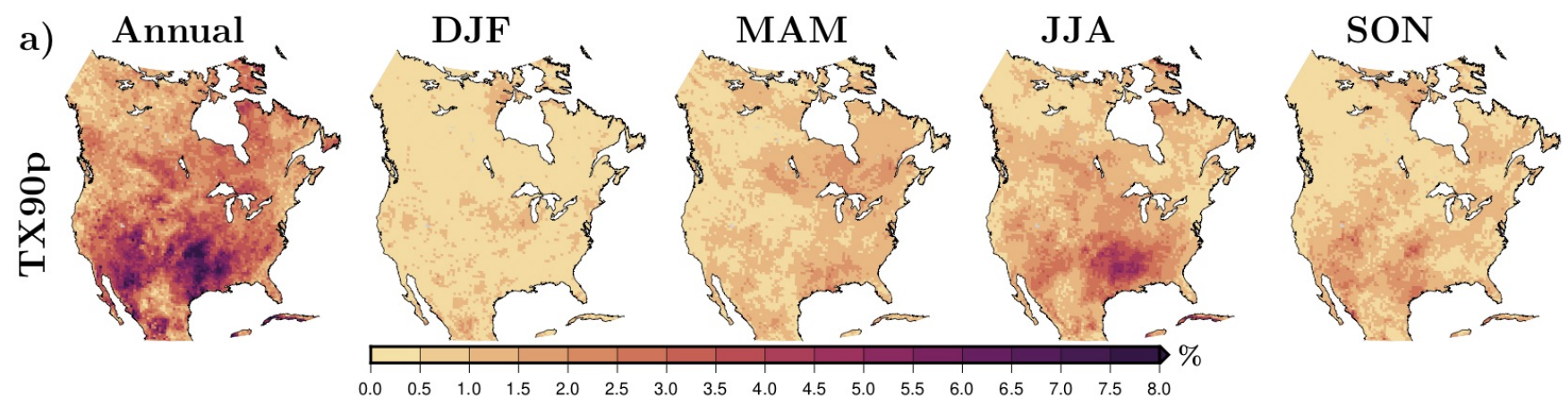

b) Annual

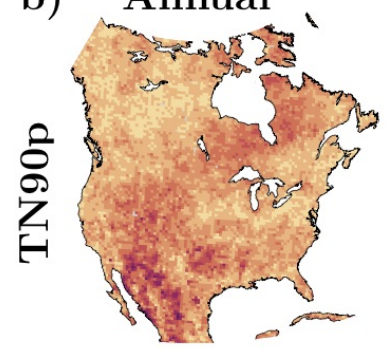

\section{DJF}

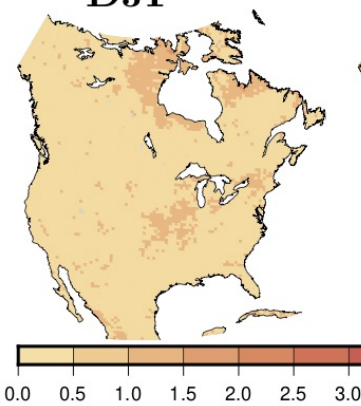

MAM

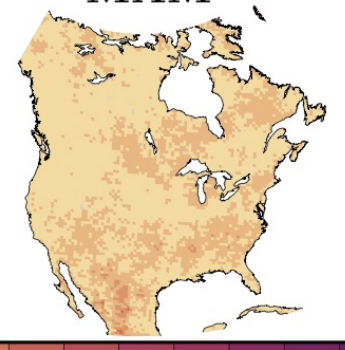

JJA

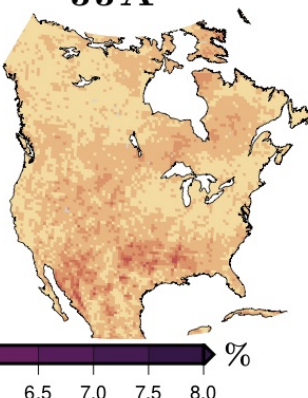

c) Annual

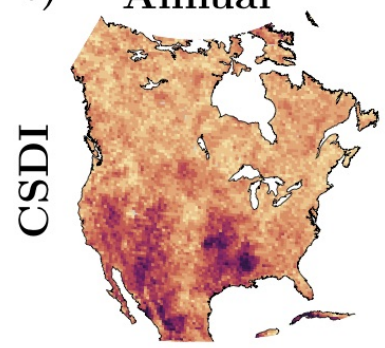

DJF

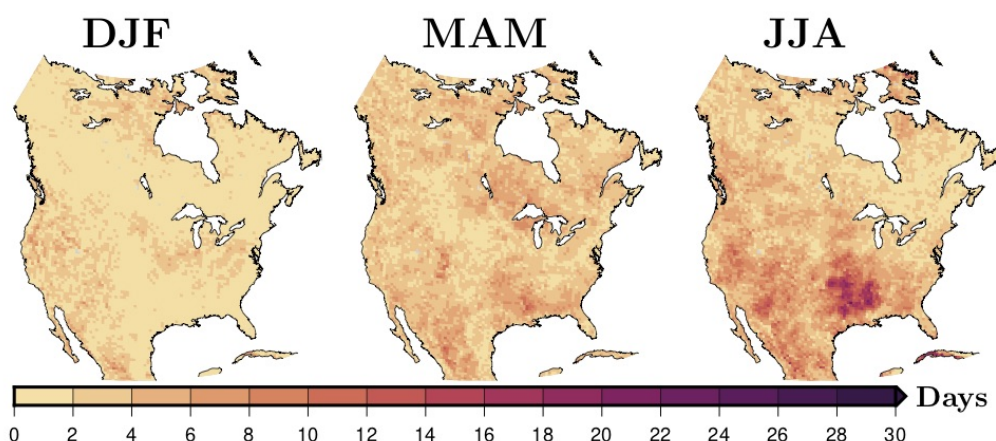

Figure S9. As in Figure S8 but for warm temperature extremes.
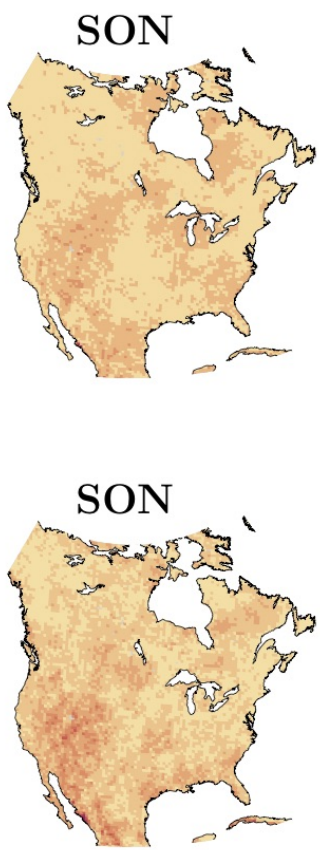


\section{PRECIPITATION INDICES}
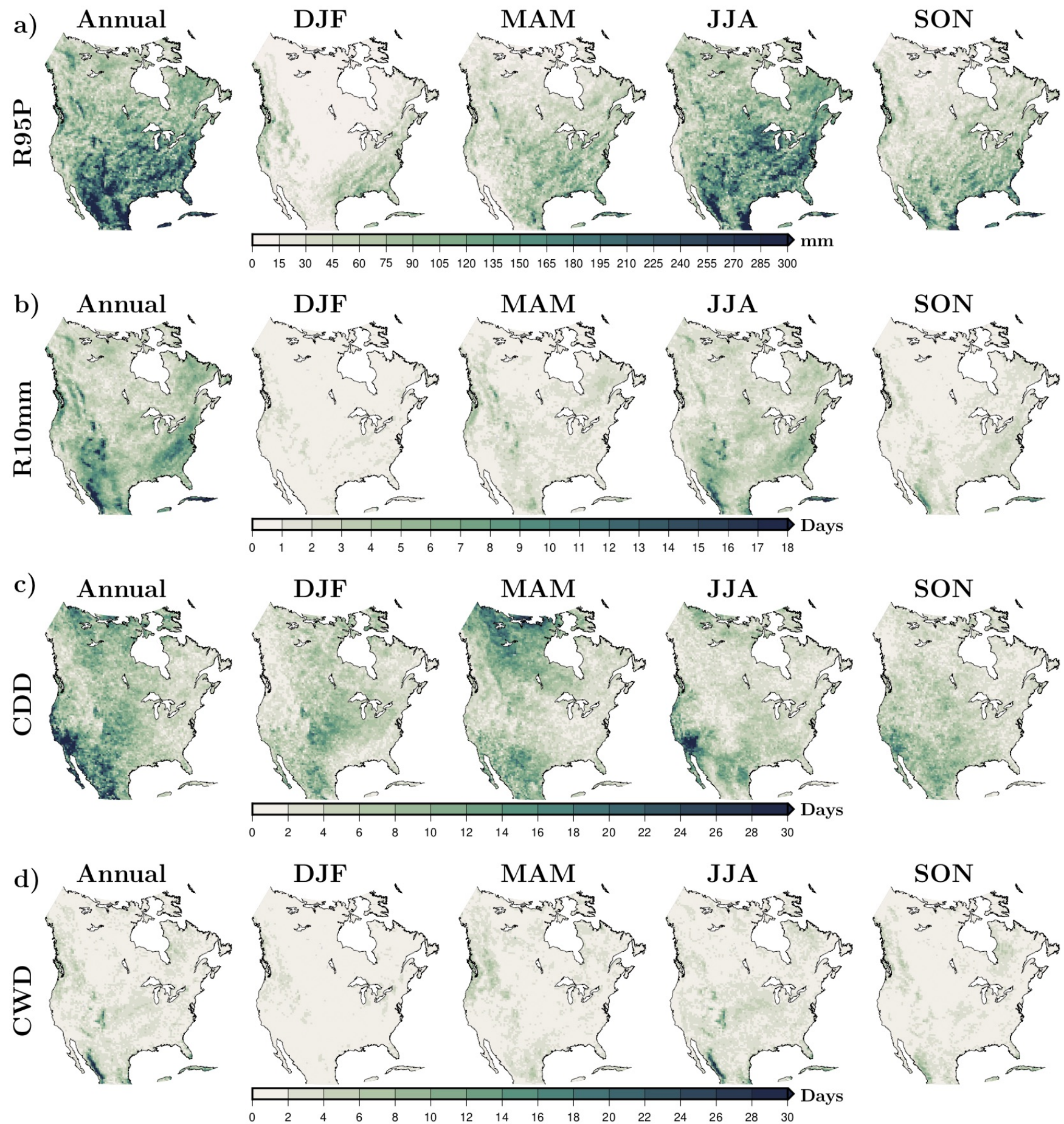

Figure S10. As in Figure S8 but for precipitation extremes. 


\section{Cold Events}
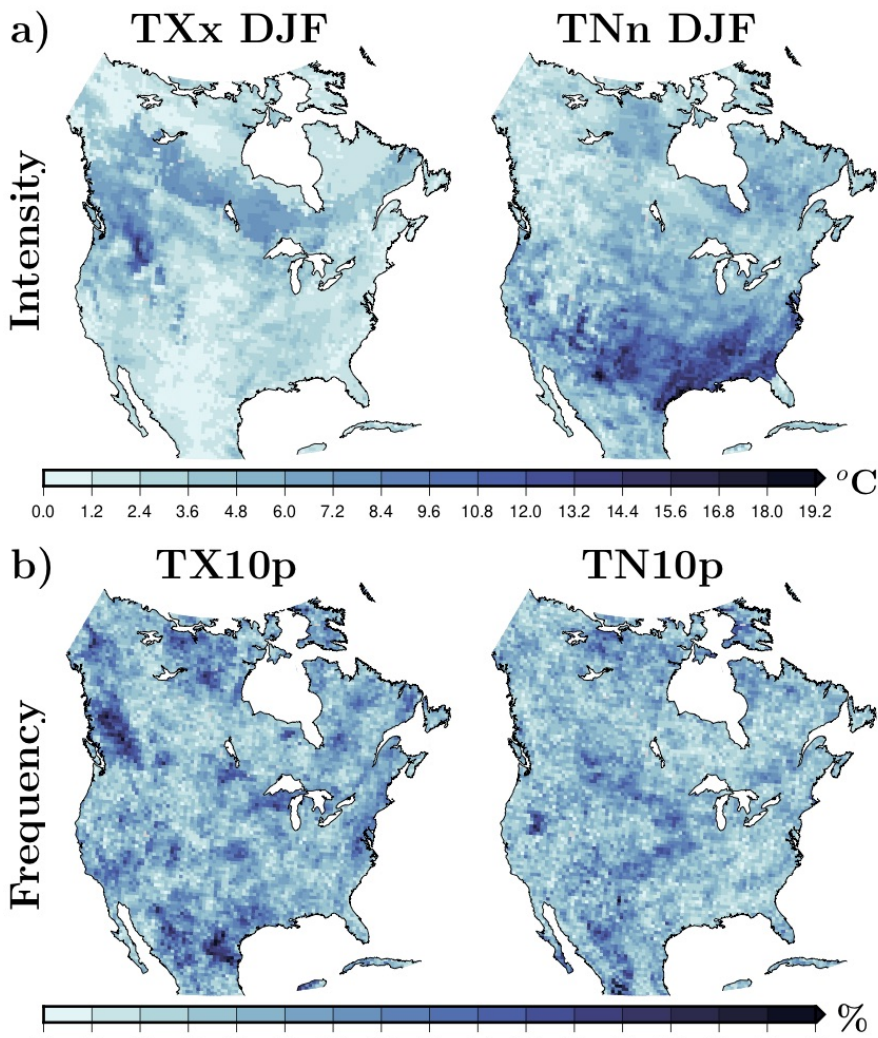

$\begin{array}{lllllllllllllllll}0.0 & 0.6 & 1.2 & 1.8 & 2.4 & 3.0 & 3.6 & 4.2 & 4.8 & 5.4 & 6.0 & 6.6 & 7.2 & 7.8 & 8.4 & 9.0 & 9.6\end{array}$

c

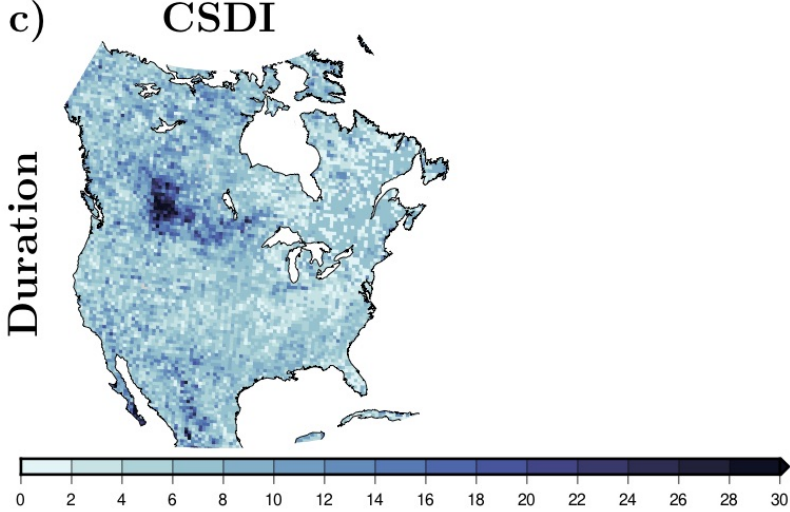

\section{Warm Events}
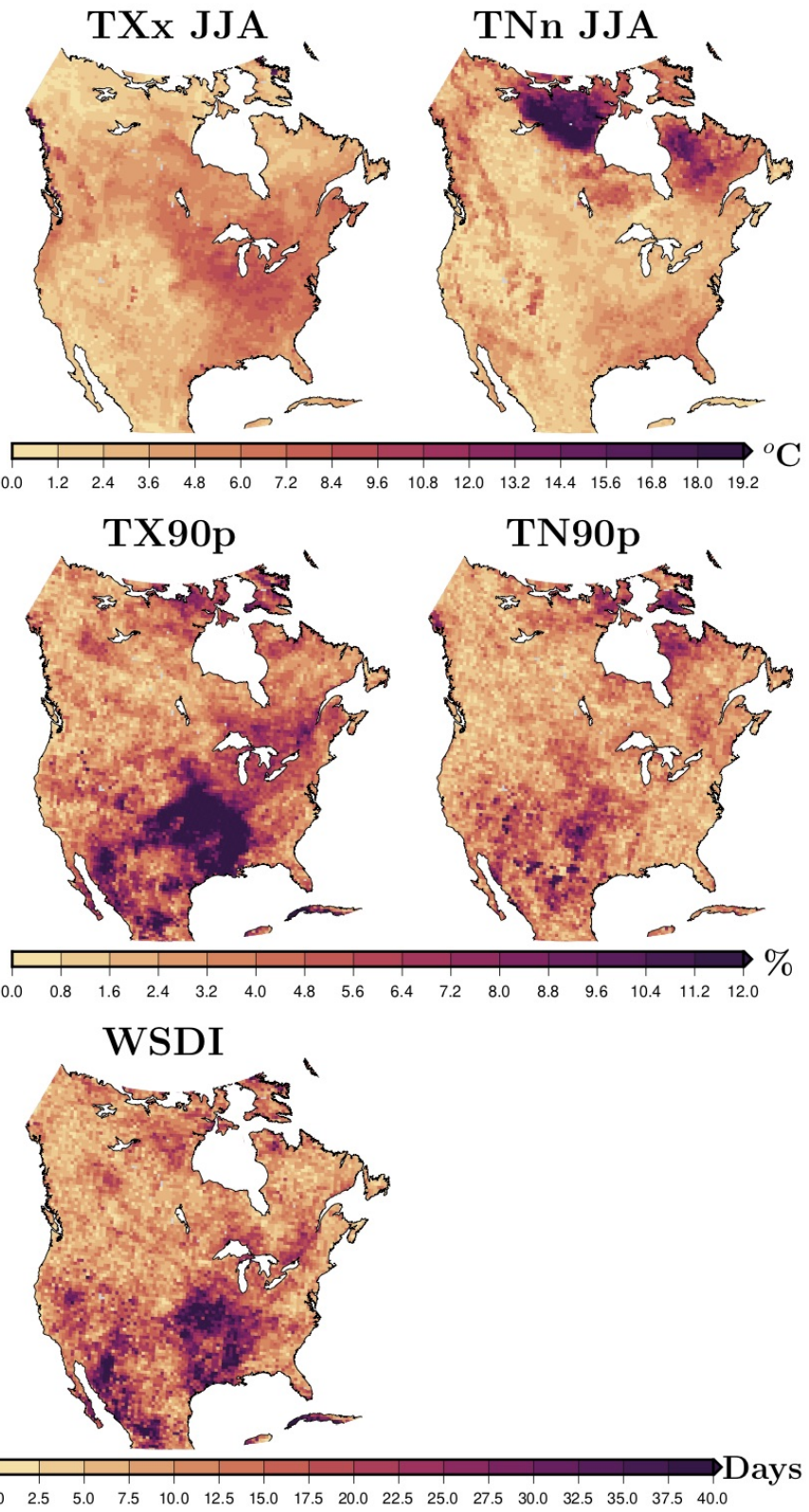

Figure S11. Multi-model ranges across the WRF simulations (i.e., difference between the highest value and the lowest value of the simulation ensemble at each grid cell) of extreme indices associated with the intensity (a), frequency (b), and duration (c) of cold (left) and warm (right) extreme temperature events (Table 2). The range among simulations is computed using the 95th percentile of each index from 1980 to 2012 for each simulation, except for the TNnDJF and TNnJJA index for which the 5th percentile of the period was employed. 


\section{Precipitation Events}
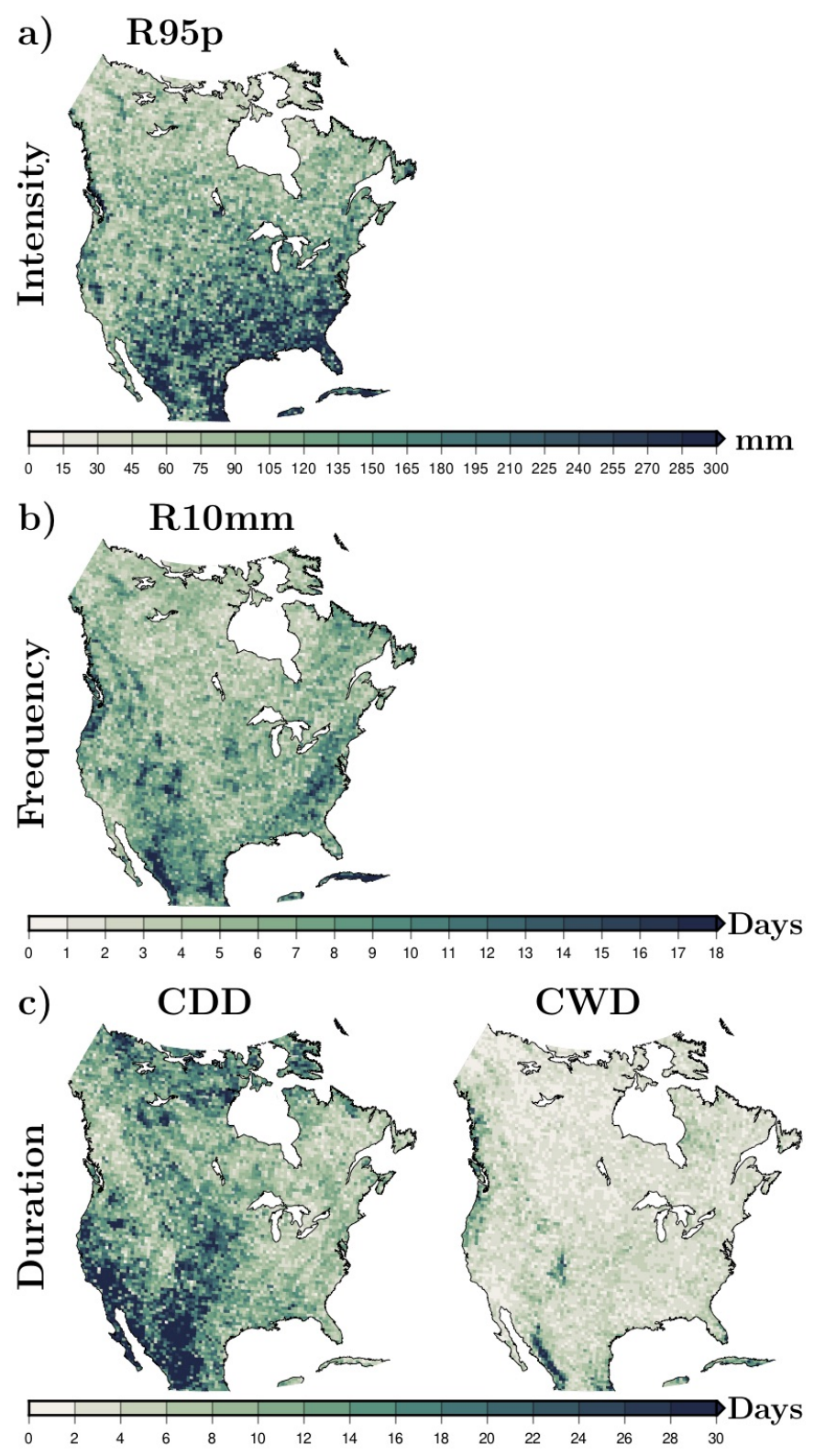

Figure S12. Multi-model ranges across the WRF simulations (i.e., difference between the highest value and the lowest value of the simulation ensemble at each grid cell) of extreme indices associated with the intensity (a), frequency (b), and duration (c) of extreme precipitation events (Table 2). The range among simulations is computed using the 95th percentile of each index from 1980 to 2012 for each simulation. 

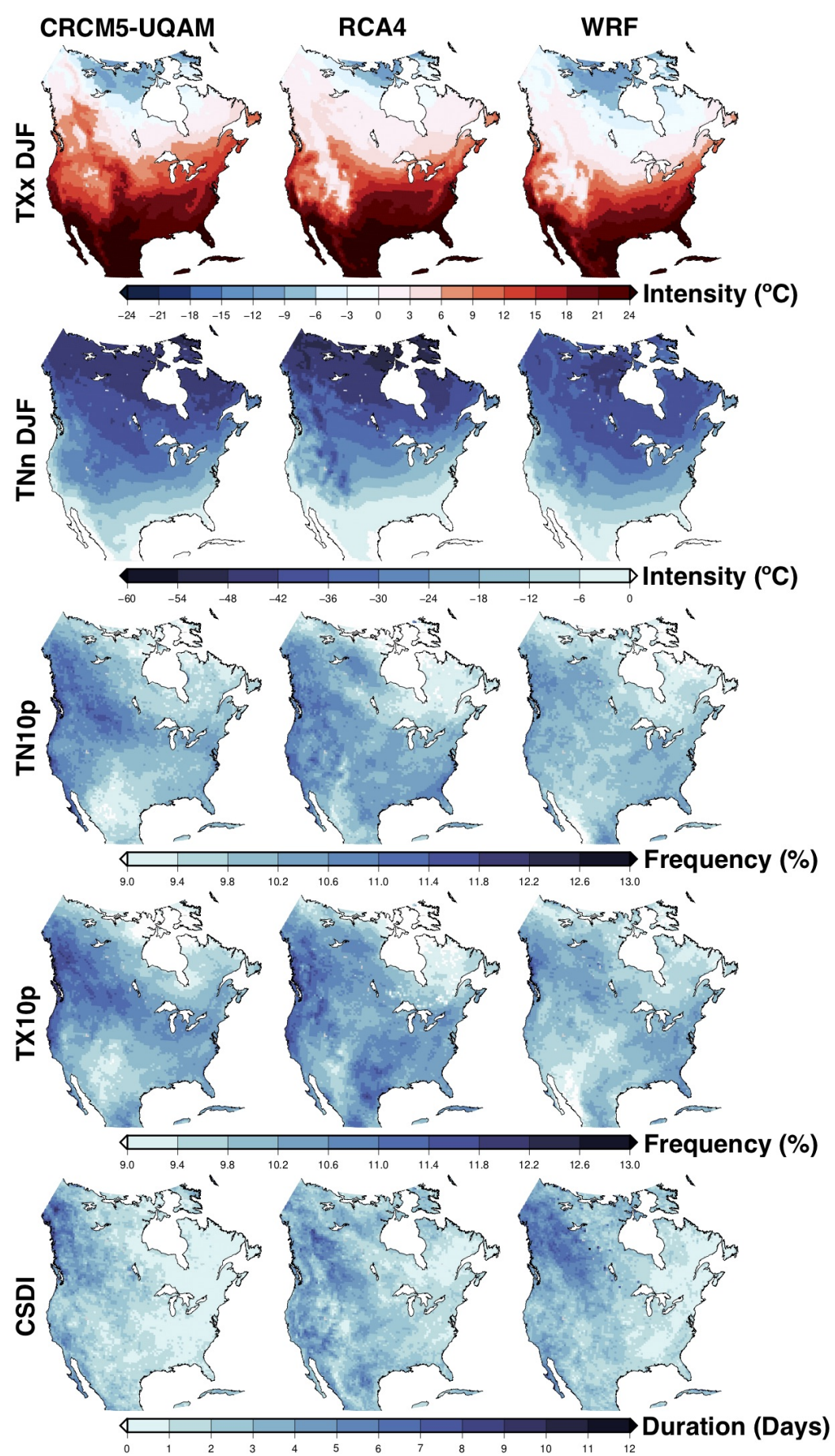

Figure S13. Climatologies of extreme indices associated with intensity, frequency, and duration of cold extreme temperature events for each simulation separately (Table 2). The indices are computed using the mean of each index from 1980 to 2012 for each simulation. 

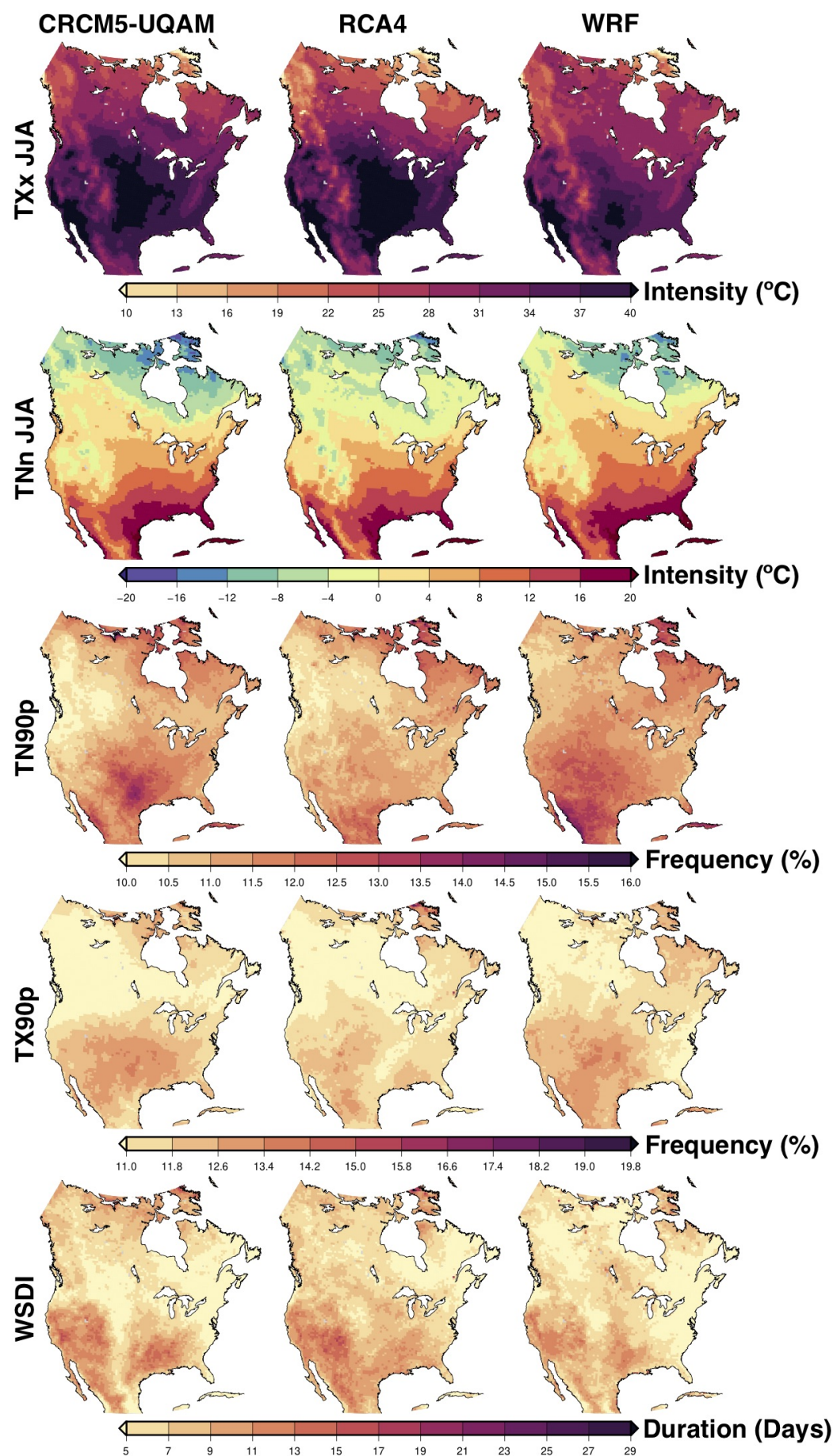

Figure S14. As in Figure S13 but for warm temperature extremes. 

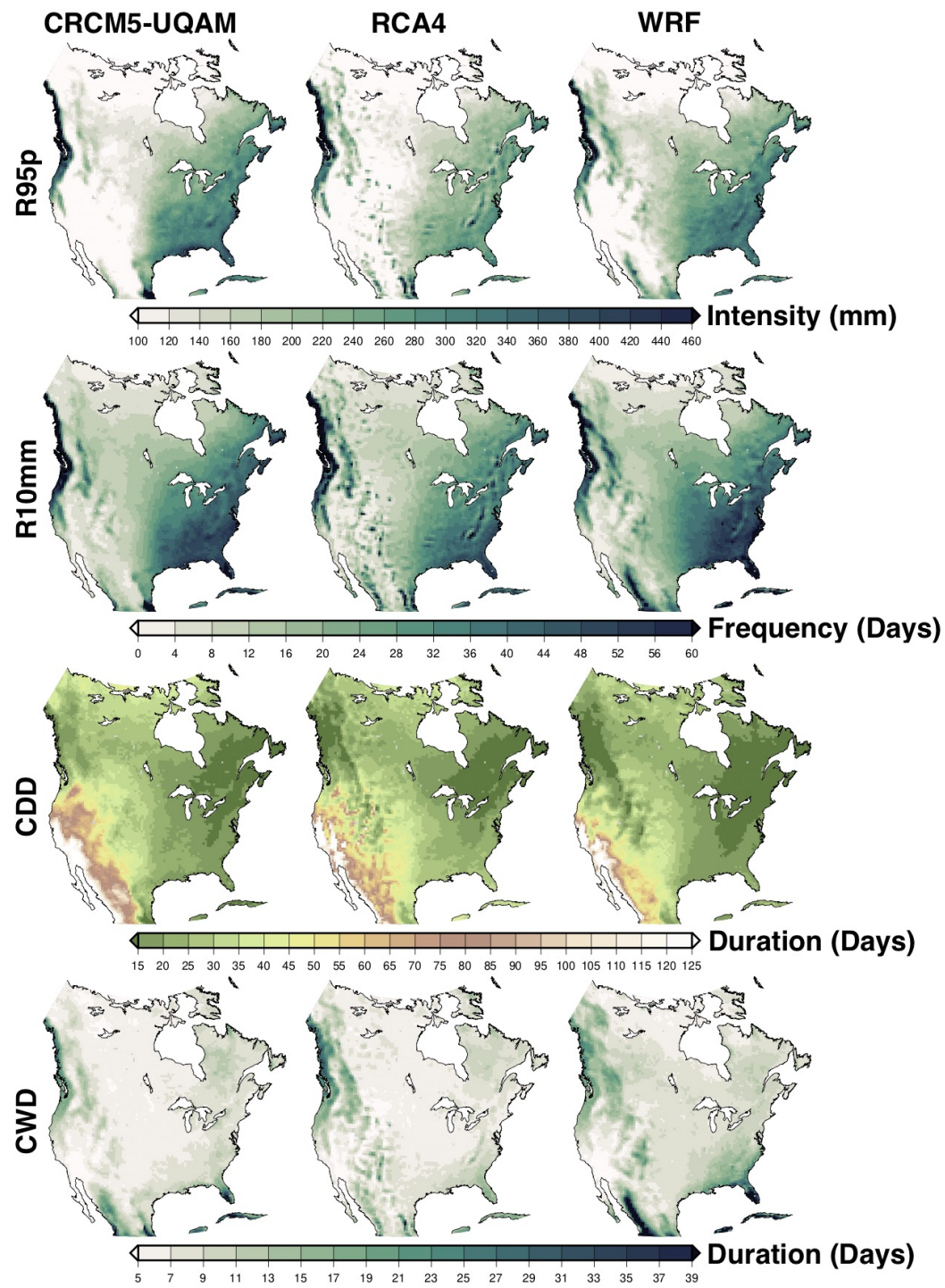

Figure S15. As in Figure S13 but for precipitation extremes. 


\section{WRF ranges - CORDEX ranges}
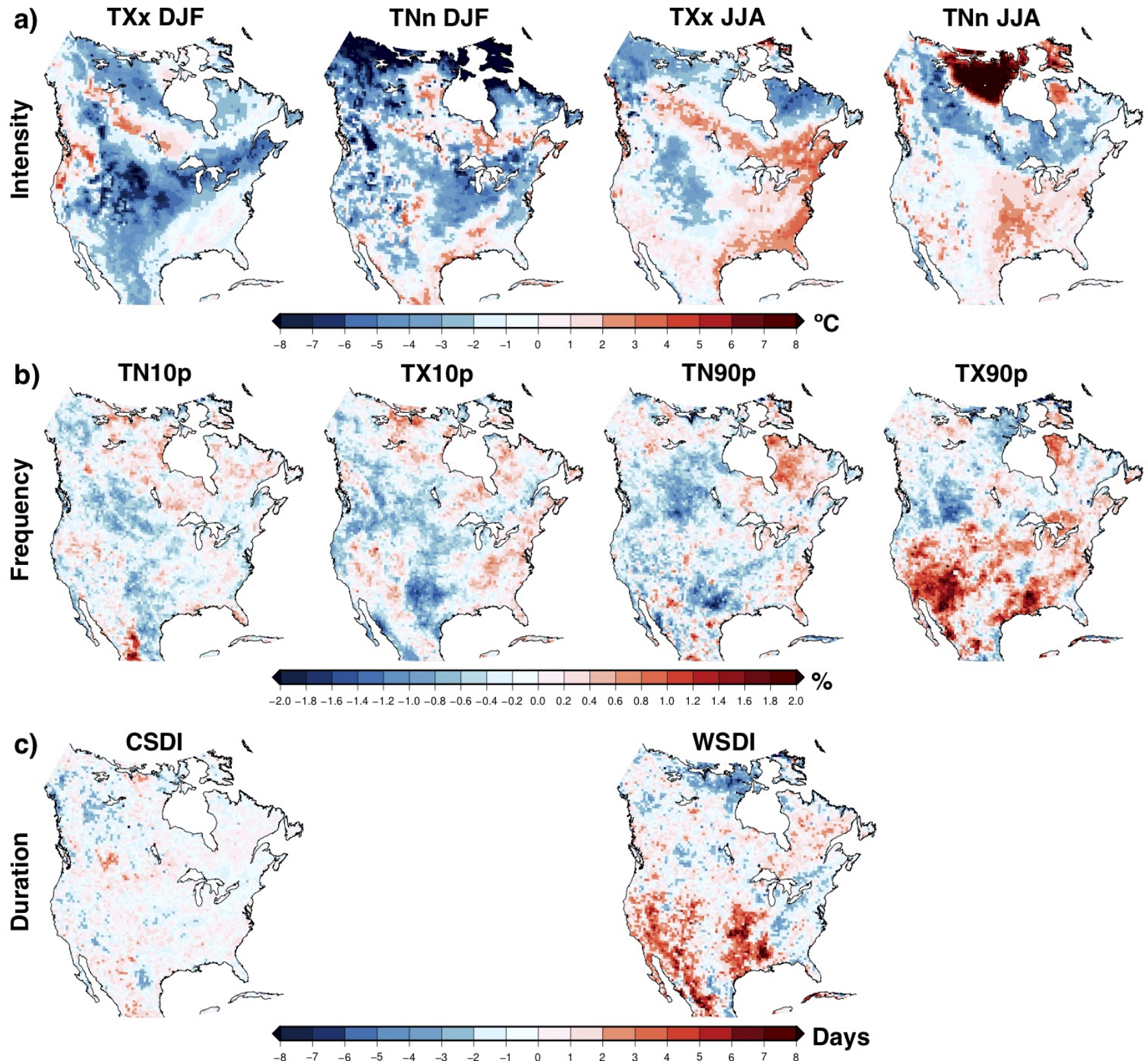

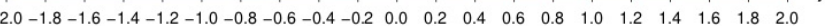

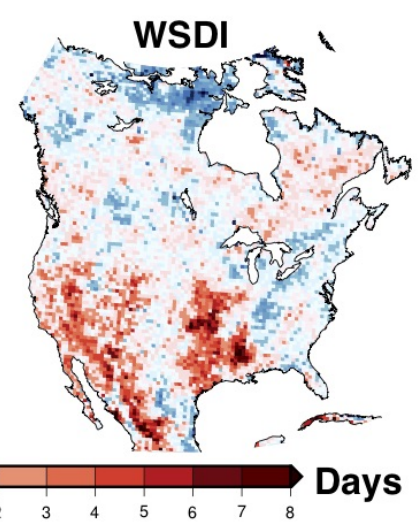

Figure S16. Differences between the range among the WRF simulations and the range among three CORDEX simulations in representing extreme indices related to intensity (a), frequency (b), and duration (b) of cold (left two columns) and warm (right two columns) extreme temperature events (Table 2). Ranges across each simulation ensemble are computed using the mean of each index from 1980 to 2012 for each simulation. Red color means larger rages among the WRF simulations than among the CORDEX simulations, white color means comparable values for ranges among the WRF simulations and the CORDEX simulations and blue color means larger ranges among the CORDEX simulations than among the WRF simulations. 

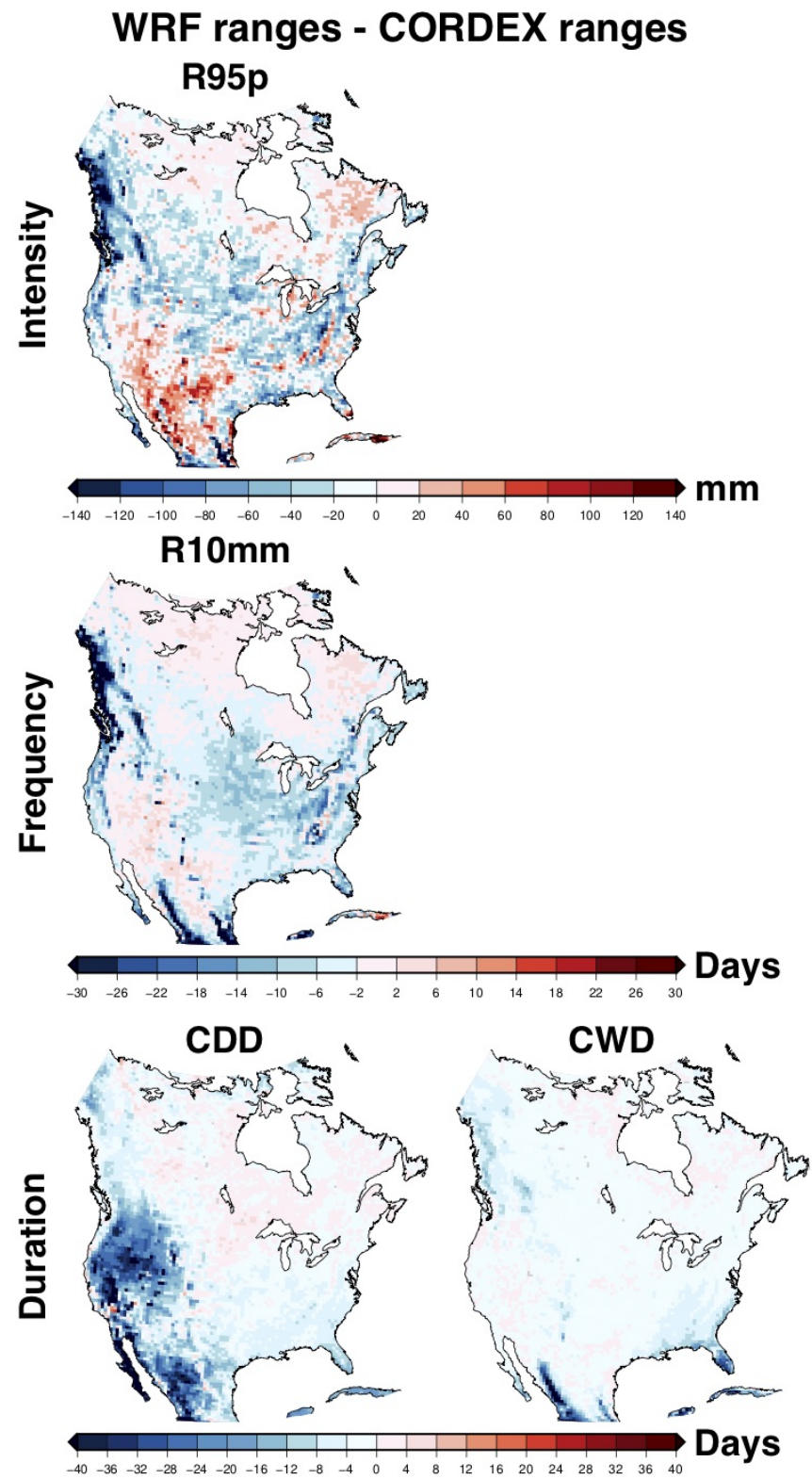

Figure S17. As in Figure S16 but for precipitation extremes. 


\section{References}

Martynov, A., Laprise, R., Sushama, L., Winger, K., Šeparović, L., and Dugas, B.: Reanalysis-driven climate simulation over CORDEX North America domain using the Canadian Regional Climate Model, version 5: model performance evaluation, Climate Dynamics, 41, 2973-3005, https://doi.org/10.1007/s00382-013-1778-9, 2013.

5 Samuelsson, P., Jones, C. G., Willén, U., Ullerstig, A., Gollivik, S., Hansson, U., Jansson, C., Kjellström, E., Nikulin, G., and Wyser, K.: The Rossby Centre Regional Climate model RCA3: model description and performance, Tellus A, 63, 4-23, https://onlinelibrary.wiley.com/ doi/abs/10.1111/j.1600-0870.2010.00478.x, 2011.

Skamarock, W. C., Klemp, J. B., Dudhia, J., Gill, D. O., Barker, D. M., Duda, M. G., Huang, X.-Y., Wang, W., and Powers, J. G.: A description of the advanced research WRF version 3, NCAR Technical Note, Tech. rep., National Center for Atmospheric Research, Boulder, Colorado, USA, 2008. 